\title{
Advance High Strength Steels: The Solution in Lightweighting our Future Automobiles
}

\author{
Firas J. Khusiafan* \\ Mechanical and Marine Engineering, Liverpool John Moores University, UK \\ Received 12 May 2018, Accepted 14 July 2018, Available online 17 July 2018, Vol.8, No.4 (July/Aug 2018)
}

\begin{abstract}
Aircraft industry's focus is mainly given on the balance between essential aspects that can make vehicles ideal for users: safety, maximum fuel efficiency, value for money, recycling and recovery of end-life vehicles, and the ability to reduce greenhouse gas emissions. This paper presents AHS:, its material properties, advantages and disadvantages, issues and some recent developments in this material for it to be considered as the "future" of automobile industry. Some comparisons are also presented to provide basic differentiation of this material from other lightweighting material types. In order to provide credible information, literature search was conducted using significant keywords in Google Scholar and journal repository Deepdyve. Current grades of AHSS are already standing out as evidenced by 2016 cars that are majorly made of this type of material. It has high strength, ductility, high energy-absorption ability and costs lower than other type of lightweighting materials. Its properties coupled with cost and environmental advantages make it more preferable relative to Aluminum In terms of Lightweighting capability, Steel particularly AHSS has the possibility to reduce 40-50\% of the weight of body components
\end{abstract}

Keywords: Maximum fuel efficiency, value for money etc.

\section{Introduction}

Automobile industry has been religious in their pursuit of improving the performance of their product vehicles. To achieve this goal, researchers in this industry have found a route of solution with Lightweighting or reduction of vehicle's mass. According to Montalbo et al (2009), "lightweighting is an important design strategy in vehicle development. By reducing vehicle mass, designers can not only improve a vehicle's performance or fuel economy, but also offset the mass of additional vehicle features such as a hybrid powertrain, in order to maintain performance." US Department of Energy (2015) gives a quantitative figure on and stated that "a 10\% reduction in vehicle weight can result in a 6\%-8\% fuel economy improvement". This fuel efficiency optimization also translates to the ability to reduce $\mathrm{CO} 2$ and GHG emissions which is favorable in the aspect of compliance on environmental regulations. Bhardwaj (2014) added that every kilogram of weight reduced in a vehicle, there is about $20 \mathrm{~kg}$ of carbon dioxide reduction. Light weighting is therefore an art of reducing through integration and substitution of parts and materials with strategic material selection (Montalbo et al ., 2009).

*Corresponding author's ORCID ID: 0000-0003-4289-2927 DOI: https://doi.org/10.14741/ijcet/v.8.4.15
Decades ago, the primary use of steel was in vogue as this material is appropriate in terms of its properties, it is relatively cheap, and readily available. But as lightweigting approach came into light, other materials had been increasingly used instead replacing some components with these to achieve the desired reductions while maintaining performance. But Steel rejuvenated itself as Advanced High Strength Steel was born to meet these challenges and retain its stance in automotive industry in the form of a stronger type of steel that can satisfy property needs in this industry.

The aim of this paper is to present AHSS, its material properties, advantages and disadvantages, issues and some recent developments in this material for it to be considered as the "future" of automobile industry. Some comparisons are also presented to provide basic differentiation of this material from other lightweigting material types.

\section{Review of Related Literature}

As industrial changes occur and different priorities were taken into account, the criteria in materials selection for automobile manufacturing are not only dependent on one factor such as customer requirements. Rather, a balanced solution between some critical factors such as improved usability at minimum power input, decreased greenhouse gas emissions as part of the industry's agreement with 
state legislations, and more no-fail safety features, are being explored (Bhardwaj, 2014). In parallel with this, other important and critical aspects also set a bigger weight of influence in automobile design and production. With these variables and goals, the move to lightweighting strategy became an instant approach to provide this balanced solution with an additional consideration on the cost and value of money. In lightweighting, researchers generally converge on this three way step in reducing mass: decrease thickness, material density and surface, with the two former elements highly dependent on the material.

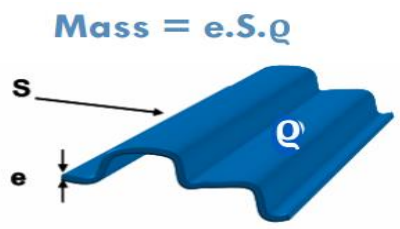

Figure1: General Strategy for Lightweighting (Blain, 2012)

As seen of Figure 2, the projection for average vehicle mass from 2010 to 2020 suggests decreasing mass which confirms the general trend in automobile design and materials selection.

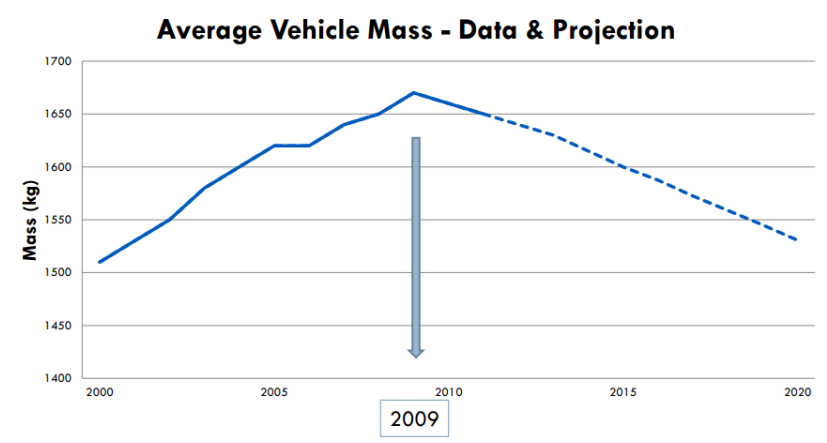

Figure 2: Projection for Average Vehicle Mass from 2010 to 2020 (Blain 2012)

Table 1: Technical Targets in Vehicle Lightweighting by 2022 (US Department of Energy, 2013)

Vehicle Lightweighting 2022 Targets

\begin{tabular}{|l|c|c|c|c|}
\hline \multicolumn{1}{|c|}{ E } & Body & Interior & $\begin{array}{c}\text { Chassis/ } \\
\text { Suspension }\end{array}$ & $\begin{array}{c}\text { Total } \\
\text { Vehicle }\end{array}$ \\
\hline $\begin{array}{l}\text { Weight } \\
\begin{array}{l}\text { Reduction } \\
\text { Target }\end{array}\end{array}$ & $35 \%$ & $5 \%$ & $25 \%$ & $30 \%$ \\
\hline
\end{tabular}

\subsection{Steel's Coming of Age}

Throughout history, steel, as one of the most common alloy, had been a major player in the automobile composition because of its properties: strength, adaptability, workability, physical finish, and most of all cost (Baluch, Mohamed Udin and Abdullah, 2014). Figure 3 was adapted from Organization for Economic
Co-operation and Development (OECD) and shows the historical composition estimate of vehicles since 1906 to 2007. The figure also depicts that steel specifically low carbon type is a major component since 1912.

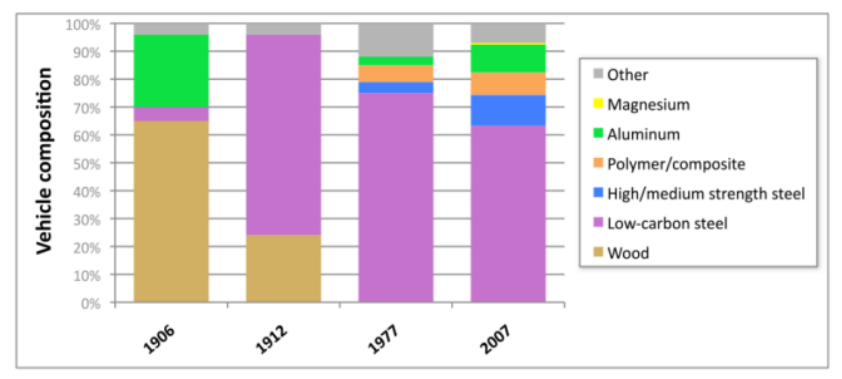

Taub et al, 2007

Figure 3: Vehicle Composition from 1906 to 2007 (Blain, 2012)

As early as 1926, steel had conquered automobile industry as the use of this material in the manufacturing of chassis and automobile bodies started and had actually comprised $15 \%$ of global steel consumption (National Steel Car, 2015; Rogers, 2009). In 1929, the shift from having primarily wooden automobiles to steel automobiles had set off (National Steel Car, 2015). It can be seen that in 1977 and 2007, majority of vehicles composition is still low carbon steel. As an example, $99.9 \%$ of all the main structure of automobiles termed as Body in White or BIW is made of welded steel (Bhardwaj, 2014). But it is significant to note that in 2007 , the fraction of lightweight materials particularly aluminum, polymer/composite, and high strength steel have prominently increased. Though the use of this steel has not been completely eliminated, more and more automobile parts are now being replaced with alternatives that can promote weight reduction without compensating rigidity (Auto World: Materials Tech/ Vehicle Lightweight, 2014). These materials include aluminum and $\mathrm{Al}$ matrix composites, magnesium, carbon fiber composites, titanium, glass fiber composites, and advanced high strength steels. Currently, the balance between the aspects stated are carefully considered and so far, advanced High Strength Steel or AHSS is considered the future of all lightweighting materials as it transformed to adapt and meet the new challenges in this industry.

\subsection{The Rebirth of Steel as AHSS}

Starting 2012, additional AHSS in pounds per vehicle had continuously increased and this material has proven to be in vogue in the latest automobile designs as shown in Figure 4.

Steels used in the automotive industry are classified into two metallurgical categories: low strength steels (interstitial-free and mild steels) and high strength steels (HSS) with the latter kind subdivided into conventional high strength steel and the newer type termed as AHSS. 
AHSS continues its growth trajectory with approximately 254 pounds per vehicle in 2014 , surpassing our estimates in 2010 for 2014 by over 20 pounds per vehicle (prio 2014 estimate was 232 Pounds)

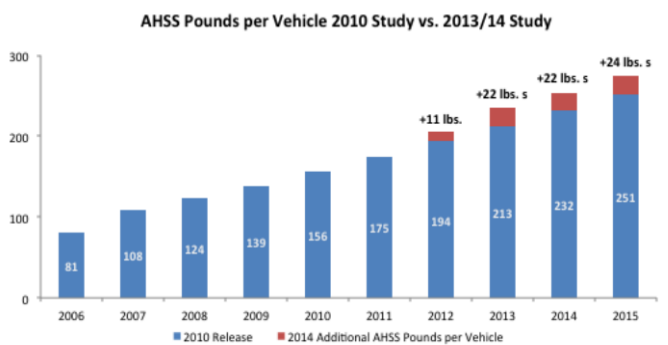

Figure 4: AHSS in pounds per vehicle from 2006 to 2015 (Blain, 2012)

Conventional HSS are single phase ferritic steels. On the other hand, AHSS are multi-phase steels: dual phase steels, complex phase steels, TRIP steels, TWIP steels, PFHT, ferritic bainitic, hot formed, and martensitic steels (Keeler and Kimchi, 2014). According to AZO Materials (2014), "All AHSS grade steels are manufactured by controlling the cooling rate and chemistry from the austenite or from the austenite and ferrite phase. This is performed either in the cooling part of the continuous annealing furnace (for hot-dip coated products) or on the hot mill's runout table (for hot-rolled products)".

Bhardwaj (2014) stated that "high strength steel accounts for the largest percentage of total tons of lightweight materials consumed, followed by aluminum and plastics." The widespread of utilization of this metal has started to be prominently present specifically on the top competing brands of cars. For 2016, Chevrolets Camaro and Colorado Diesel with $70 \%$ AHSS was awarded as the bearer of 2016 Motor Trend Car and Truck of the Year (Meeting The Challenge-Lightweighting With Steel, 2014). Additionally, 2016 Chevrolet Malibu utilized AHSS and reduced 300 pounds of weight relative to the 2015 model even there was a four inch increase in the wheelbase (Anderton, 2015). Hyundai Tucson, Kia Optima, and Nissan Maxima 2016 models are designed to be lighter but more rigid with the use of AHSS (Anderton 2015).

\section{Recommendation}

In automobile production, Brown and David (1993) emphasized that the "materials are at the core of every decision throughout the described productdevelopment process". Other attributes considered will now be lined up by priority: application, target user, market, item budget, and many others. In lightweighting strategy, materials selection is main consideration to identify the possible application, design and options for production scheme (Brown and David, 1993). AHSS had given manufacturers a future and promising insight of lightweighting automobiles. Modern AHSS has the combination of properties that are ideal for cars manufacturing: it has comparable properties relative to expensive material alternatives such as aluminum and plastics, and higher degree of flexibility offering an advantage to optimize any component structure. It has a relatively high strength, ductility, and high energy-absorption ability (Kuziak, Kawalla, and Waengler, 2008).

In vehicles, AHSS is used automotive exteriors: panels such as foods, doors and fenders, for general vehicles Body in White (BIW) structures, chassis, and suspensions (Suehiro 2013). Its ability to carry variable loads (static and dynamic) in any case of crash event makes it suitable for the main structure of vehicles that acts like a safety cage for passengers (Keeler and Kimchi, 2014).

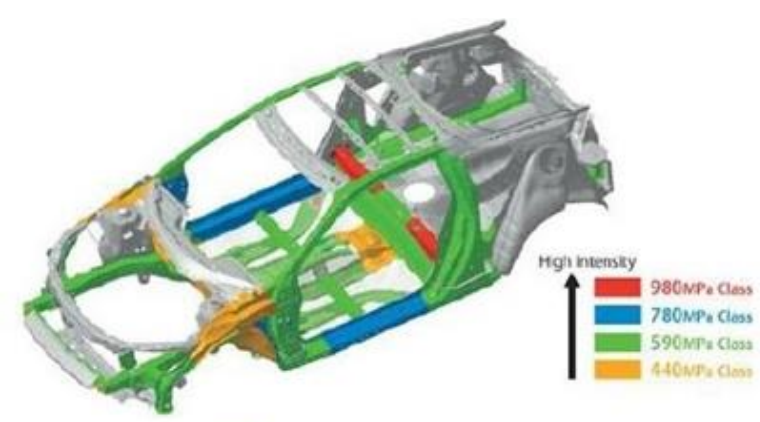

AHSS in the 2011 Honda CR- $\mathrm{Z}^{\mathrm{H}-4}$

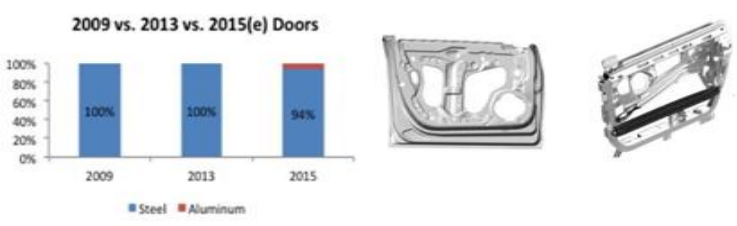

Figure 5: AHSS in 2011 Honda Car, Material Composition of Vehicle Doors from 2009 to 2015

(Abraham 2015; Keeler and Kimchi, 2014)

For panels, the complexity of shape and plastic deformation resistance requirements ranges from flat to complex. For specific flat surface parts, Suehiro (2013) emphasized that "surface deflection and dent resistance are important factors for foods and doors". To suppress surface deflections, low yield strength is to be achieved and as opposed to that approach and to improve dent resistance, yield strength is increased (Suehiro, 2013). To balance such, high strength steel sheets are bake hardened to offer ideal formability, final yield strength and eventually good dent resistance (Seal 2006; Suehiro, 2013). On the other hand, the preference on utilizing high strength steel sheets with over 780 Mpa strength level poses an advantage on energy absorption capability of the end product while the total mass is reduced (Suehiro, 2013). Figure 5 stipulates the performance requirements, material properties to meet, evidence of performance, and the potential steels that can be selected for major crash zones of a vehicle. Figure 6 on the other hand explicitly shows the differences in tensile strengths of conventional Steels and AHSS. Also, tensile strengths of 
different types of AHSS are also given and emphasizes the high strength of this material especially for $3^{\text {rd }}$ generation AHSS.
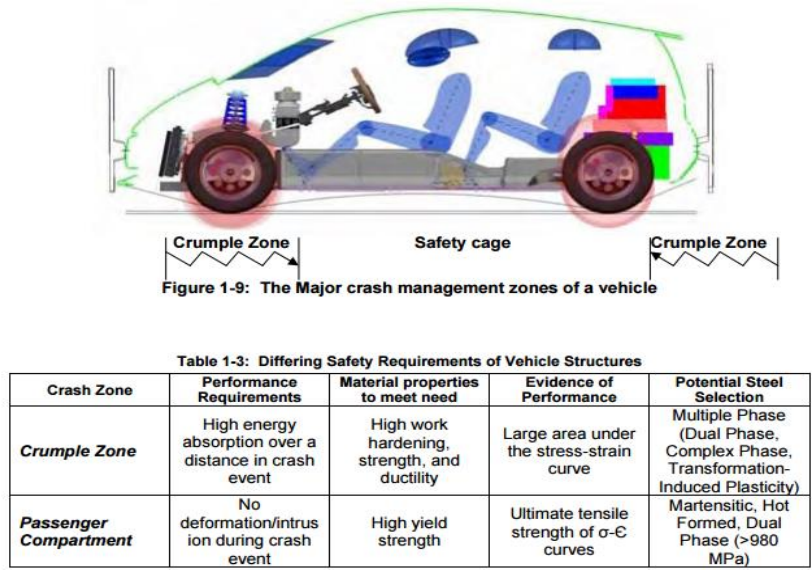

Figure 6: Crash Zone Requirements and Material Options (Keeler and Kimchi, 2014)

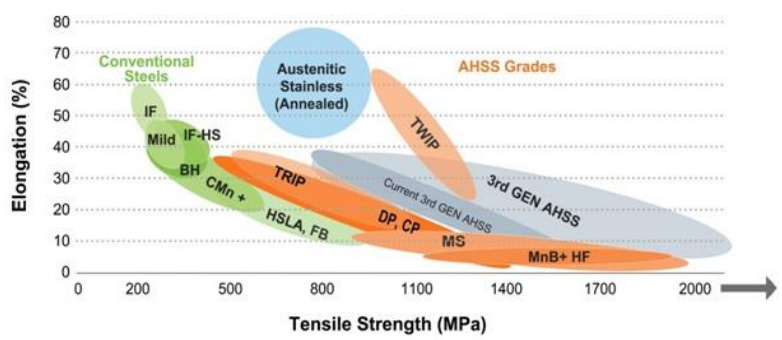

Figure 7: Tensile Strength Difference for Conventional and AHSS (Keeler and Kimchi, 2014)

The major competitor of AHSS in automobile industry is aluminum followed by these secondary options: magnesium, carbon fiber, and plastics and polymer composites. Aluminum can reduce a component weight by $60 \%$, has a low density at $2.77 \mathrm{~g} / \mathrm{cm}^{3}$, high ductility, high tensile strength of 207-552 $\mathrm{MPa}$, moderate modulus of elasticity of $69-76 \mathrm{GPa}$, and elongation of $10-30 \%$ (Campbell, 2012). But this material is more costly according to MIT from production, manufacturing, and assembly to cost per mass reduced. Compared to AHSS, it is two to three times more costly its manufacturing and assembly higher by 20 to $30 \%$ (Steel Market Development Institute, n.d). Lastly, Steel Market Development Institute (n.d.) added that "mass reduction with steel can be achieved at nearly zero cost, while engineering studies show low-density materials like aluminum cost $\$ 2.75$ or more per pound saved". In addition to this disadvantage, Campbell (2012) added that aluminum's fatigue strength is sometimes "much lower than static strength and Highstrength $\mathrm{Al}$ alloys can be difficult to weld. In terms of environmental emissions, global warming potential, and energy usage, the table below shows significant difference between producing aluminum and steel, the former being energy extensive, higher ton $\mathrm{CO} 2$ and $\mathrm{SO} 2$ eq/ton produced. In terms of recyclability, AHSS is $100 \%$ recyclable.
Table 2: Comparison on Energy Emissions for Steel versus Aluminum Production (Demeri, 2013)

\begin{tabular}{|c|c|c|c|}
\hline Material & Energs, G.Vten & $\begin{array}{l}\text { Global warming potential, } \\
\text { toa } \mathrm{CO}_{2}^{\text {esquten }}\end{array}$ & $\mathrm{SO}_{y} \in \mathrm{Qq} \mathrm{kg} / \mathrm{ten}$ \\
\hline $\begin{array}{l}\text { Steel } \\
\text { Aluminum }\end{array}$ & $\begin{array}{l}21.6 \\
155\end{array}$ & $\begin{array}{r}2.01 \\
11.06\end{array}$ & $\begin{array}{r}5.12 \\
50.43\end{array}$ \\
\hline Sorrce:AUTK & Atet Development & & \\
\hline
\end{tabular}

In summary, properties profile of AHSS is as follows making it possible to have the following performance characteristics according to Tamarelli (2011):

Table 3: Summary of AHSS Strength Properties (Tamarelli, 2011)

\begin{tabular}{|cc|}
\hline Yield Strength & $>300 \mathrm{MPa}$ \\
Tensile Strength & $>600 \mathrm{MPa}$ \\
\hline Absorption Potential, UTS & $<1000 \mathrm{Mpa}$ \\
\hline
\end{tabular}

- "Excellent formability and weldability" using conventional equipment

- "High UTS for given strength, delays necking"

- "Good manufacturability"

- "Good in dynamic loading conditions"

- "Very high UTS High energy absorption and resistance to deformation High residual Crash safety components deformation capacity"

- "High wear resistance Good durability"

The issues with AHSS are mainly on its workability and are quite significant especially when dealing with complex geometries. Case in point, complex shaped parts produced by deep drawing has the possibility to incur fracture and wrinkle during the process thereby causing surface deflections (Keeler and Kimchi, 2014; Suehiro, 2013). But metallurgical solution is already available on this. Another issue is the local failures during AHSS formation since this material is a multiphased component of steel and phase changes occur during deformations (Baluch, Mohamed Udin and Abdullah, 2014). Additionally, lubricant breakdown also occurs during formation which increases scrap rates and tool maintenance therefore the overall cost fo production (Baluch, Mohamed Udin and Abdullah, 2014).

\section{Conclusion}

Currently, the focus of research in AHSS is centered upon the $3^{\text {rd }}$ generation AHSS with higher tensile strength as depicted from Figure 7. Current grades of AHSS are already standing out as evidenced by 2016 cars that are majorly made of this type of material. Its properties coupled with cost and environmental advantages make it more preferable relative to Aluminum. If successful, the third generation AHSS may now be the real future of automobile industry and can therefore transform manufactured automobiles that can comply more on the requirements set by countries specifically on emissions. In terms of Lightweighting capability, Steel particularly AHSS has 
the possibility to reduce $40-50 \%$ of the weight of body components (Brown and David, 1993). Though steel has higher density of about $7.2 \mathrm{~g} / \mathrm{cm} 3$, still massive but its strength sets it apart allowing thinner sheets utilization while still attaining the required properties of the end product. Therefore, in Figure 1, although the material density is the same but thickness can now be reduced thereby reducing the total mass.

Steel, though it has partially rebirthed itself will now be the main choice in the material selection. Though there are some issues during the process of forming AHSS, studies are also now centered on improving each issues encountered.

\section{References}

Abraham, A. (2015). Brown, W. and David, A. (1993). Material Selection Processes in the Automotive Industry. First ed. [eBook] pp.1-35. Available at: http://deepblue.lib.umich.edu/

Anderton, J. (2015). Aluminum Versus Steel: Ferrous Fights Back with AHSS. [Online] Available at: http://www.engineering.com/

Auto World: Materials Tech/ Vehicle Lightweight. (2014). [video] USA: US Department of Energy.

AZO Materials, (2014). Advanced High Strength Steels for Cars. [online] Available at: http://www.azom.com/ article.aspx?ArticleID $=11250 \# 2$

Campbell, F. (2012). Lightweight materials. Materials Park, Ohio: ASM International.

Baluch, N., Mohamed Udin, Z. and Abdullah, C. (2014). Advanced High Strength Steel in Auto Industry: an Overview. Engineering, Technology \& Applied Science Research, 4(4), pp.686-689.

Bhardwaj, B. (2014). The Complete Book on Production of Automobile Components \& Allied Products. Delhi, India: Asia Pacific Business Press Incorporated, pp.9-35.
Blain, P. (2015). Steel Perspectives for the Automotive Industry. First ed. [eBook] pp.1-22. Available at: http://www.oecd.org/industry/ind/50498824.pdf

Brown, W. and David, A. (1993). Material Selection Processes in the Automotive Industry. First ed. [eBook] pp.1-35. Available at: $h t t p: / / d e e p b l u e . l i b . u m i c h . e d u /$

Steel Market Development Institute. [eBook] Available at: http://www.autosteel.org/ /media/Files/Autosteel/Great\% 20Designs\%20in\%20Steel/GDIS\%202015/Track\%202\%20\%20Abraham.pdf

Keeler, S. and Kimchi, M. (2014). Advanced High-Strength Steels Application Guidelines. First ed. [eBook] World Auto Steel. Available at: http://www.rackcdn.com/ AHSS_Guidelines_V5.0_20140514.pdf

Kuziak, R., Kawalla, R. and Waengler, S. (2008). Advanced high strength steels for automotive industry. Archives of Civil and Mechanical Engineering, 8(2), pp.103-117.

Meeting The Challenge - Lightweighting With Steel. (2014). [video] Steel Market Development Institute.

Montalbo, T., Lee, T., Roth, R. and Kirchain, R. (2009). Selection of lightweighting strategies for use across an automaker's vehicle fleet. IEEE International Symposium on Sustainable Systems and Technology, pp.1-6.

National Steel Car, (2015). [online] Available at: https://www.steelcar.com/timeline

Rogers, R. (2009). An economic history of the American steel industry. London: Routledge.

Seal, R.K. (2006) New Ultra-Low Carbon High Strength Steels with Improved Bake Hardenablity for Enhanced Stretch Formability and Dent Resistance. Master's Thesis, University of Pittsburgh.

Suehiro, M. (2013). Application technologies for effective utilization of advanced high strength steel sheets. AIP Conference Proceedings.

Steel Market Development Institute, (n.d.). The Facts: Steel vs. Aluminum. First ed. [eBook] Available at: http://www.autosteel.org/ /media/Files/Autosteel/MBS

US Department of Energy, (2015). Vehicle Technologies Office: Lightweight Materials for Cars and Trucks Department of Energy. [online] Energy.gov. Available at: http://www.energy.gov/eere/ 